\title{
Study of mast cells in appendicitis: possible significance
}

\author{
Sharan A. ${ }^{1}$, Ingole N.S. ${ }^{2}$ \\ ${ }^{1}$ Dr. Anita Sharan, Associate Professor, Department of Pathology, D Y Patil Medical College, Nerul, Mumbai, ${ }^{2}$ Dr. N.S. Ingole, \\ Ex. Professor Department of Pathology MGIMS Sewagram, Wardha, Maharashtra, India.
}

Corresponding Author: Dr. Anita Sharan, Associate Professor, Department of Pathology, D Y Patil Medical College, Nerul, Mumbai, Maharashtra, India. Email: anitsharan@gmail.com

\begin{abstract}
Background: To study the mean mast cell count per square $\mathrm{mm}$ field in different layers of appendix and to correlate the relationship of these with progression of disease and extent of fibrosis. Also to study the possible significance of mast cell counts with different histological changes and relation with clinical presentation. Material and Methods A total of 120 cases of appendix comprised of 20 cases of normal appendix which served as the control and 100 cases of appendicitis in different phase of evolution of the disease were studied for mast cell counts and its significance was assessed in correlation with the histopathological diagnosis as per the evolution of the disease. Results: Mast cell counts in submucosa were always higher then in mucosa or in muscular propria both in normal and in pathological appendicitis. The increased mast cell count in the mucosal layer was statistically significant in organizing phase than in chronic appendicitis. Submucosal mast cell count did not show any statistically significant difference between different stages of appendicitis and normal appendicitis. The mast cell count in muscularis propria showed statistically significant increase in chronic appendicitis as well as in early acute phase. In appendicitis with grade 2,3 and 4 histology, the total mean mast cell count/sq $\mathrm{mm}$ was much higher than in range in grade 1 and grade 5 . Conclusion: In acute phase of inflammation there is decrease in the mast cell. In chronic phase of inflammation there is increase in the mast cell counts. A significant increase of mast cells in muscularis propria during early acute phase of appendicitis which was observed in present study has not been described in literature. This finding needs further evaluation to explain the role of mast cells in the development of early acute inflammatory response.
\end{abstract}

Keywords: Appendicitis, Evolution, Mast Cell, Histopathological Diagnosis Muscularis Propria

\section{Introduction}

Appendicitis remains a common disease especially in the young. It continues to attract the surgeon's knife for clinical relief and the pathologist's microscope for answers to the causative factors. Although the lumen obstruction is widely regarded as the major pathogenic mechanism for the development of appendicitis, little is known about the way in which the inflammatory injury proceeds.

It is now well established that the intestinal mucosa plays an essential role in the first line of defense against intraluminal microbial pathogens or chemical agents. Sanyal suggested mast cells to play role in development of firbrosis.

The earlier disruption of mast cells may cause liberation of histamine, and thereby increase vasodilatation and capillary permeability and thus help in forming the inflammatory exude. The later proliferation of mast cells and invasion of the inflamed are is followed by development of fibrosis [1].

Manuscript received: $16^{\text {th }}$ October 2019

Reviewed: $26^{\text {th }}$ October 2019

Author Corrected: $4^{\text {th }}$ November 2019

Accepted for Publication: $8^{\text {th }}$ November 2019
The practice of early appendicectomy for clinically suspected appendicitis has resulted in decreased morbidity, but both the surgeon and pathologist are aware that a significant proportion of appendices that are removed show no evidence of inflammation. This discrepancy between clinical presentation and lack of definite morphological change is confounding. Since appendicectomy relieves symptoms in most of these patients, it is likely that a yet unknown causative pathologic condition exists in the appendices of these patients $[1,2]$.

The findings of mast cells in increased number in appendix, their recent ultrastructural features and study of granule content and its various inflammatory and immunologic response alterations have suggested that mast cells may be involved in the pathogenesis of appendicitis (Dvorak et al, Fox et al, Freidman and Kaliner). Crow and Howe studied the mast cells numbers in appendices with threadworm infestation, using a long toluidine blue staining method. They found a considerable variation in the mast cell numbers from case to case and could not correlate the mast cell numbers and the presence of thread worms [2-5].

Pathology Update: Tropical Journal of Pathology \& Microbiology Available online at: www.medresearch.in 903 | P a g e 
The present study has been done to find out the relationship of mast cells with evolution of appendicitis and co-relative it with extent of fibrosis. The study of mast cell, fibrosis and its relationship to the number and degranulation may help in deciding the role of these cells in pathogenesis of appendicitis.

\section{Materials and Methods}

Study design/Type of study period: The present study was carried out in the department of Pathology, Mahatma Gandhi Institute of Medical Sciences, Sewagram from January 2001 to June 2002.

Sample Size: In the present study 100 specimens of surgically resected appendices with histopathological evidences of appendices were studied for mast cell counts in different layers of the appendix and its significance was assessed in correlation with the histopathological diagnosis as per the evolution of the disease. The cases of gangrenous appendicitis were excluded from the study. This was compared with 20 normal appendices collected from surgical material received in histopathology section from patients who presented with clinical symptomatology of appendicitis. These cases were also graded histologically for the extent of fibrosis and the mast cell counts in these cases was correlated with the grade of the disease and the extent of fibrosis.

Inclusion criteria: All appendices surgically resected as a therapeutic measure for clinically suspected appendicitis and appendices removed in the course of laparotomy done for other diseases were included.

Exclusion criteria: The clinical date including name, age, sex, registration number of the patient, name of the consultant and clinical history including duration of illness, clinical examination findings, investigation reports and other relevant data was obtained prior to the processing of the specimens. The surgical specimens were received fresh in $10 \%$ forma saline as fixative. The gross examinations were noted.

Data collection procedure: There section of approximately2-3 mm thickness were obtained as under.

1. One cross section from proximal on third close to the surgical margin.

2. One cross section from the middle one third and

3. On longitudinal section from the distal on third of the Appendix.

All the three sections were processed in one block for routine paraffin section. From each block, three sections of $4^{\text {th }}$ thickness were cut on the rotary microtome: one section was stained with routine Haematoxylin and Eosin staining
(Culling et al, 1985), other one was stained with $1.0 \%$ toludine blue for mast cell count and the third section was spared for repeat staining in case it was required.

(A) Heamatoxylin and Eosin staining

Nuclei RNA rich cytoplasm, calcium

Muscle, fibrin, keratin

Collagen

Blue

Red blood cells

Bright red

Pink

Orange red

(B) Toludine blue staining method $\mathrm{pH} 4.5$

Metachromatic substances

red, pink or purple

Nuclei and other components

Blue

The mast cell granules were deeply stained with a violet metachromasia against a pale blue background.

Data analysis: The $\mathrm{H} \& \mathrm{E}$ stained section was examined microscopically for the final histopathological diagnosis. The cases were grouped into normal and different categories of appendicitis as per the evolution of the process as under.

1) Normal appendix

2) Appendicitis

A) Early acute appendicitis (catarrhal)

- Marginating neutrophils in lamina propria as well as small collections in the lumen

- Mucosal ulceration may or may not be present.

B) Acute appendicitis (suppurative)

- All coats congested, oedematous

- Necrosis or ulceration of the mucosal layer.

- Increased number of neutrophils in mucosa cyptitis and crypt abscesses

- Submucosa is inflamed, infiltrated with neutrophils.

- Muscularis propria is inflamed, infiltrated with neutrophils.

- Extensive suppuration - gangrene - focal defects in wall - perporation - periappendicial abscess and periappendicitis - peritonitis

C) Organizing phase of acute appendicitis (healing phase)

- Granulation tissue (mixture of acute and chronic inflammatory cells and young connective tissue).

D) Chronic appendicitis

- Lymphocytes and plasma cells in the muscularis propria and serosa.

- No significant acute inflammation

E) Other benign lesions - such as Mucocele, Tubercular appendicitis and other miscellaneous benign lesions.

In the $\mathrm{H} \& \mathrm{E}$ stained section from 20 appendices which were histologically normal but had symptomatology of appendicitis the degree of fibrosis was assessed and graded 
Ethical approval: Taken

Statistical Analysis: After getting the required information, the collected data were coded, tabulated and analysed. The various statistical techniques i.e. the mean, standard deviation and test of significance (t-test and chisquare-test) were used for drawing valid conclusions.
Statistical analysis done using student t-test. SPSS 13.0 software was used to calculate $\mathrm{p}$ value. $\mathrm{P}<0.05$ was taken as statistically A descriptive analysis was done on all variables to obtain a frequency distribution. The mean $+\mathrm{SD}$ and ranges were calculated for quantitative variables. Continuous variables were compared by the Student $t$ test. Proportions were analyzed with the chi-square test

\section{Results}

The present study was carried out in the Department of Pathology, Mahatma Gandhi Institute of Medical Sciences, Sewagram during the period of January 2001 to June 2002, to assess the significance of mast cell counting in cases of appendicitis with respect to progression of disease and the extent of fibrosis.

A total of 120 cases of appendix comprised of 20 cases of normal appendix which served as the control and 100 cases of appendicitis in different phase of evolution of the disease were studied for mast cell counts, as shown in Table 1. Thus, the mast cell counts with clinical presentation of pain, vomiting and guarding were more or less comparable. However, because of little variation in the total mast cell counts, these findings were not subjected for statistical analysis.

Acute phase followed by organizing phase of appendicitis were more commonly seen. Only $8 \%$ cases had histology of chronic appendicitis in the present study. On evaluation of H \& E stained section in 20 histologically normal appendicitis for histological grading of fibrosis, 5 cases each were seen in grade 2 and grade 3 . In 3 cases there was no evidence of inflammation of fibrosis [Table 1-2].

Table-1: Showing distribution of total 120 cases included in the present study.

\begin{tabular}{|ll|c|}
\hline \multicolumn{2}{|l|}{ Histological Diagnosis } & Number of cases \\
\hline Normal appendix & & 20 \\
\hline Appendicitis & Early Acute Appendicitis & 100 \\
& $-\quad$ Acute Appendicitis & 15 \\
& $-\quad$ Organizing phase of Appendicitis & 41 \\
& $-\quad$ Chronic Appendicitis & 34 \\
& $-\quad$ Tubercular Appendicitis & 2 \\
\hline Total & & $\mathbf{1 2 0}$ \\
\hline
\end{tabular}

Table-2: Showing distribution of 20 cases as per the histological grade and extent of fibrosis. ( $\mathrm{N}=\mathbf{2 0})$

\begin{tabular}{|c|l|c|}
\hline Grade & Histological Assessment & Number of cases \\
\hline 1 & $\begin{array}{l}\text { Normal appearing sample with thin muscularis mucosa and submucosa and no } \\
\text { evidence of inflammation of fibrosis }\end{array}$ & 3 \\
\hline 2 & $\begin{array}{l}\text { The appearance of loose connective tissue in the deep lamina propria, frequently } \\
\text { pericryptal and containing few inflammatory cells. However eosinophils were } \\
\text { always conspicuous in these areas. }\end{array}$ & 5 \\
\hline 3 & $\begin{array}{l}\text { Disruption of the muscularis mucosa by loose 'connective tissue' and the } \\
\text { appearance of small neural and vascular elements in the superficial submucosa } \\
\text { which also exhibited increased fibrosis. }\end{array}$ & 5 \\
\hline 4 & $\begin{array}{l}\text { Similar to grade } 3 \text { but with more extensive involvement of the submucosa by } \\
\text { mature fibrous tissue so that the lumen had become narrowed }\end{array}$ & 3 \\
\hline 5 & $\begin{array}{l}\text { Extensive submucosal fibrosis and obliteration of the mucosa so that only a pin- } \\
\text { hole lumen or no lumen was observed. Increased fatty tissue was in some cases, } \\
\text { mixed with the sub mucosal fibrosis. }\end{array}$ & 4 \\
\hline
\end{tabular}

Pathology Update: Tropical Journal of Pathology \& Microbiology Available online at: www.medresearch.in 905 | P a g e 
There was no statistically significant difference between total mean mast cell count of normal and inflamed appendicitis. However, there was statistically significant decrease of mast cells in cases with acute appendicitis and significant increase in organizing phase of appendicitis. Mast cell counts in submucosa were always higher then in mucosa or in muscular propria both in normal and in pathological appendicitis.

Decreased mast cell count in the mucosal layer was statistically significant in organizing phase than in chronic appendicitis. The increased mast cell count in the mucosal layer was statistically significant in organizing phase than in chronic appendicitis. [Tables 3-6].

Table-3: Showing total mean mast cell counts in normal and inflamed appendicitis

\begin{tabular}{|ll|c|c|}
\hline Diagnosis & & Number of cases & Mean Mast cell count/sq.mm \\
\hline Normal appendix & & 20 & 22.04 \\
\hline Appendicitis & & 100 & 22.98 \\
& $-\quad$ Early Acute Appendicitis & 15 & 23.71 \\
& $-\quad$ Acute Appendicitis & 41 & 17.46 \\
& Organizing phase of & 34 & 26.76 \\
& Appendicitis & 8 & 25.58 \\
- & Chronic Appendicitis & 2 & 56.33 \\
& Tubercular Appendicitis & & \\
\hline
\end{tabular}

Table-4: Showing mean mast cell count in different layers of normal and pathological appendicitis.

\begin{tabular}{|c|c|c|c|c|c|}
\hline Diagnosis & No. of cases & \multicolumn{3}{|c|}{ Mean mast cell count/sq.mm (S.D.) } & $\begin{array}{c}\text { Total mean mast } \\
\text { cell /sq. mm. (S.D.) }\end{array}$ \\
\hline & & Mucosa & Submucosa & Muscularis propria & \\
\hline Normal appendix & 20 & $21.93(10.01)$ & $37.43(18.07)$ & $11.0(6.22)$ & $22.04(6.38)$ \\
\hline Appendicitis & & & & & $15.90(7.96)$ \\
\hline Early acute & 15 & $17.81(7.94)$ & $35.92(14.57)$ & $8.22(5.36)$ & $17.46(5.83)$ \\
\hline Acute & 41 & $13.03(5.94)$ & $30.30(11.620)$ & $11.89(8.32)$ & $26.76(9.20)$ \\
\hline Organizing & 34 & $28.79(10.89)$ & $42.80(13.50)$ & $17.50(8.26)$ & $25.58(8.88)$ \\
\hline Chronic & 8 & $27.25(12.88)$ & $34.57(12.20)$ & 48 & 56.33 \\
\hline Tubercular & 2 & 38 & 83 & & \\
\hline
\end{tabular}

Table-5: Showing correlation of extent of fibrosis and histological grade with mean mast cell count.

\begin{tabular}{|c|c|c|c|c|c|c|}
\hline $\begin{array}{c}\text { S. } \\
\text { No. }\end{array}$ & $\begin{array}{c}\text { Histological } \\
\text { Grade }\end{array}$ & $\begin{array}{c}\text { No. of } \\
\text { Cases }\end{array}$ & \multicolumn{3}{|c|}{ Mean mast cell count/sq.mm (S.D.) } & $\begin{array}{c}\text { Total mean mast cell } \\
\text { count/sq.mm (S.D.) }\end{array}$ \\
\hline & & & Mucosa & Submucosa & Muscularis propria & \\
\hline 1 & 1 & 3 & $15.3(5.34)$ & $14.64(5.01)$ & $6.66(3.21)$ & $12.2(6.23)$ \\
\hline 2 & 2 & 5 & $33.3(10.78)$ & $53.66(18.90)$ & $12.4(4.82)$ & $33.12(11.25)$ \\
\hline 3 & 3 & 5 & $19.3(7.67)$ & $50.1(18.26)$ & $13.5(5.92)$ & $27.7(12.88)$ \\
\hline 4 & 4 & 3 & $19.6(7.40)$ & $31.35(11.11)$ & $11.44(6.12)$ & $20.8(9.80)$ \\
\hline 5 & 5 & 4 & - & - & - & 16.4 \\
\hline & Total & 20 & $21.93(10.01)$ & $37.43(18.07)$ & $11.0(6.22)$ & $22.04(6.38)$ \\
\hline
\end{tabular}


Table-6: Age wise distribution of the cases of appendicitis for mast cell count

\begin{tabular}{|c|c|c|c|c|c|}
\hline Age in years & No. of cases & \multicolumn{3}{|c|}{ Mean mast cell counts/sq.mm } & $\begin{array}{c}\text { Total mean mast cell } \\
\text { counts/sq.mm }\end{array}$ \\
\hline & & Mucosa & Submucosa & Muscularis propria & \\
\hline $0-10$ & 2 & 13 & 16 & 9 & 12.65 \\
\hline $11-20$ & 29 & 21.9 & 37.3 & 12.5 & 25.48 \\
\hline $21-30$ & 39 & 22.34 & 35.03 & 13.75 & 23.52 \\
\hline $31-40$ & 14 & 23.16 & 38.25 & 16.00 & 27.07 \\
\hline $41-50$ & 5 & 22.6 & 40.5 & 13.25 & 23.16 \\
\hline $51-60$ & 6 & 25.0 & 34.8 & 17 & 21.96 \\
\hline$>61$ & 5 & 23.75 & 38.5 & 14 & 23.76 \\
\hline & 100 & 22.38 & 36.19 & 12.51 & 22.98 \\
\hline
\end{tabular}

Submucosal mast cell count did not show any statistically significant difference between different stages of appendicitis and normal appendicitis. The mast cell count in muscularis propria showed statistically significant increase in chronic appendicitis as well as in early acute phase. In appendicitis with grade 2,3 and 4 histology, the total mean mast cell count/sq $\mathrm{mm}$ was much higher than in range in grade 1 and grade 5 [Tables 7-8].

Table-7: Showing sex wise distribution of cases of appendicitis for mast cell counts.

\begin{tabular}{|c|c|c|c|c|c|}
\hline Sex & No. of cases & \multicolumn{3}{|c|}{ Mean mast cell count/sq.mm } & $\begin{array}{c}\text { Total mean mast } \\
\text { cell/sq.mm }\end{array}$ \\
\hline & & Mucosa & Submucosa & Muscular propria & \\
\hline Male & 67 & 22.01 & 38.35 & 13.72 & 24.6 \\
\hline Female & 33 & 21.9 & 33.96 & 14.46 & 22.88 \\
\hline
\end{tabular}

Table-8: Showing correlation of clinical presentation with total mean mast cell count

\begin{tabular}{|c|c|c|}
\hline Symptom & Total cases & Total mast cell count/sq.mm \\
\hline Pain & 108 & 29.43 \\
\hline Vomiting & 56 & 23.16 \\
\hline Diarrhea & 4 & 37.07 \\
\hline Guarding & 24 & 28.25 \\
\hline Lump & 5 & 22.9 \\
\hline Fever & 3 & 24.3 \\
\hline
\end{tabular}

No significance in the mast cell count was observed in different age groups and sex of patients. Similarly, the mast cell counts were not significantly altered with clinical presentation. Morphologically there was no variations in mast cell morphology in normal and pathological appendicitis from different layers.

\section{Discussion}

The present study entitled "Study of mast cells in Appendicitis: Possible Significance" was carried out in the Department of Pathology Mahatma Gandhi Institute of Medical Science Sewagram from January 2001 to June 2002 to study the relationship of mast cells with different stage of appendicitis and to correlate it with the extent of fibrosis.
In the present study 20 cases of normal appendicitis which were unremarkable histopathologically but submitted with clinical diagnosis of appendicitis were taken as control. Whereas the remaining 100 cases were of appendicitis in different phases of evolution of the disease. Andreou et al in 1990. Examined histopathologically 101 autopsy appendices and over 3000 surgically resected appendices. 
The authors fount that fibrosis and faecolith were more common in the older autopsy group than in the younger surgically resected group and suggested that fibrosis in appendix is an age-related change although some may be due to previous inflammation. They also pointed out that from the histological point of view may questions relating to appendix remain still unanswered [6].

T Suji et al looked into new insights about the pathogenesis of appendicitis based on immunocytochemical analysis for early immune response. In an experimental model using rabbits they found significant infiltration of Polymorphonuclear leucocytes, IgM and IgG plasma cells at 30 minutes following obstruction of appendiceal lumen. They concluded that previously unrecognized concept in the pathogenesis of appendicitis requires further elucidation of the simulating agent and in particular the $\mathrm{T}$ cell recognition process [7].

Aravindan and team compared eosinophil and mast cell counts in the muscularis mucosa of appendix using Giemsa stain in 120 consecutive appendicectomies and 20 appendicitis from medicolegal autopsies. He found an increase in mean eosiophil count in patients of acute appendicitis and also observed an evidence of mast cell degranulation. The author proposed that the disease is possibly triggered by type I hypersensitivity and infection is a later consequence [8].

In a similar study like ours, mast cell distribution in surgically resected appendices was studied to investigate their variation in normal and inflamed appendices and their possible role in the pathogenesis of appendicitis. The appendices were assessed for their histological changes and density of eosinophil and mast cell infiltration. The mast cells were counted in $1 \%$ toluidine blue stained sections.

A positive correlation was found between the mast cell and eosinophil counts. It was concluded that mast cell counts were found to be highest in acute eosinophilic appendicitis and recurrent appendicitis especially associated with fibrosis. Intermediate mast cell counts were seen in acute appendicitis and acute suppurative appendicitis. Thus, mast cells appear to play roles in accentuation of inflammatory process and fibrosis [9].

Naik et al studied mast cell count in 200 surgically resected appendices from patient aged 4 to 65 years and found that the inflammation of the appendix was associated with decreased mucosal and submucosal mast cell numbers and it was more so with acute appendicitis than subacute appendicitis. They studied the relationship of mast cells, nerves and fibrosis and found that in the mucosa, the mast ell number was greater in the early stages of fibrosis. Bothe in the mucosa and submucosa, mast cells were found closely associated with neural tissue. As the fibrosis increased this association between mast cells and neural tissue was retained only in the submucosa. [10]. Stead RH et al studied mast cells, nerves and fibrosis in the appendix and did a morphological assessment. It was seen that mast cells are closely associated with nerves in the mucosa of the appendix vermiformis, and obliteration of the appendiceal lumen by fibrous tissue is accompanied by neurogenous hyperplasia.

However, changes in the density of mast cells in this process have not been reported. Accordingly, fibrosis was graded in haematoxylin and eosin sections from 46 samples of human appendix. This was compared with mast cell number in toluidine blue-stained slides and nerve density in PGP9.5-immunoreactive sections.

In the mucosa, the mast cell number in the samples with minimal fibrosis was three times greater than in those classified as normal $(\mathrm{P}<0.0001)$, and this declined in the more fibrotic samples. In the submucosa, mast cell numbers and nerve scores were not significantly different in the different histological grades and obliterated samples resembled normal submucosa [11].

Coskun $\mathrm{N}$ et al also did similar study on mast cell density, neuronal hypertrophy and nerve growth factor expression in patients with acute appendicitis. The aim of this study was to immunohistochemically investigate the relationship between MCD, nervous system and NGF expression in the appendices of cases with clinically and histopathologically diagnosed acute appendicitis and of normal controls. Mast cell tryptase, PGP 9.5 and anti-NGF immunostained tissue sections were subjected to quantitative image analysis.

Results showed that MCD, the number of Schwann cells, the number and size of ganglia and NGF staining were significantly greater in acute appendicitis than in the control group $(p<0.01$. Findings indicate that mast cells could be one of the important cell populations responsible for nerve proliferation and hypertrophy in acute appendicitis [12].

Role of Eosinophils, mast cells, nerves and ganglion cells in appendicitis. was studied by Singh UR, Malhotra A et al. Twenty to thirty percent appendices removed from patients with suspected appendicitis appear normal on histology.

The cause of pain in these patients is unknown. The presence of eosinophils and mast cells should be looked at skeptically which may explain the cause of pain. A significant increase in Eosinophils, mast cells, nerves and ganglion cells was seen in acute appendicitis. Increase in eosinophils and mast cells may explain the pain in histologicaly normal but clinically suspected acute appendicitis [13]. 
A quantitative immunophenotypic alanalysis was done by Amber S, Mathai AM et al. Neuronal hypertrophy and mast cells in histologically negative, clinically diagnosed acute appendicitis was seen. In about $20-25 \%$ of appendicectomies performed for clinically suspected acute appendicitis, definite morphological changes are lacking on histopathological examination. The present study was done to investigate whether any changes in neurons and mast cells could be detected in patients presenting with clinical acute appendicitis but found to have normal appendix at histopathology. Neuronal hypertrophy and mast cells may play a role in the pathogenesis of appendicitis-like pain in patients with histologically normal appendices [14].

Nemeth et al (2001) studied appendix specimens for the expression of inflammatory markers as an indicator of presence of an inflammatory response in the subgroup of patients whose appendices appeared normal on histologic examination, using immunofluro-histochemistry using confocal laser microscopy. They confirmed the existence of a subgroup of appendicitis within the so called histologically normal appendices in which the evidence of an inflammatory pathologic condition is only obvious at the molecular level. The initiating signal for this and all other forms of clinical appendicitis still remains elusive [15].

Mast cells in surgically resected appendices were also studied by Mysorekar VV, Chanda S et al. Mast cells are known to be effector cells in various inflammatory reactions, but their role in appendicitis is unclear. The present study was undertaken to investigate the extent of mast cell involvement in appendicitis and evaluate their possible role. The mast cells were counted in $1 \%$ toluidine blue-stained sections. Mast cell counts were lowest in normal appendices, significantly higher in acute appendicitis $(\mathrm{P}<0.01)$ and highest in chronic appendicitis $(\mathrm{P}<0.001)$. A Type I hypersensitivity reaction with release of mediators by mast cells might be another triggering factor for the sequence of events leading to appendicitis [16].

Acute phase ( $41 \%$ cases) followed by organizing phase (34\% cases) were seen more commonly and only $8 \%$ cases had chronic appendicitis in the present study. It is well known that the chronic inflammation of the appendix is rare and the great majority of the appendices labelled as showing chronic appendicitis are really examples of healing after a mild acute attack, thus supporting the findings in the present study.

\section{Limitation of the present study}

1. Small sample size

2. Chances of bias

3. Single center trial

\section{Conclusion}

The following conclusions were drawn from the present study:

1. In acute phase of inflammation there is decrease in the mast cell counts which may be due to degranulation resulting in local tissue inflammatory response and edema probably due to histamine and other mediators released by mast cells.

2. In chronic phase of inflammation there is increase in the mast cell counts.

3. A significant increase of mast cells in muscularis propria during early acute phase of appendicitis which was observed in present study has not been described in literature. This finding needs further evaluation to explain the role of mast cells in the development of early acute inflammatory response.

4. It is important to evaluate the interactions between mast cell and different components of tissue systems to know pathophysiology of inflammatory as well as noninflammatory fibrotic disease.

\section{What this study adds to the existing knowledge?}

The mast cell density in appendix increases significantly during the initial stages of fibrosis and it subsequently declines until the mucosa is obliterated by the fibrous tissues. It will be interesting to determine whether similar parallel changes in mast cells are observed in other fibrotic processes specially those involving gastrointestinal tract, particularly in crohn's disease.

The alteration in the mast cell counts are because of histological process associated with the disease rather than the clinical features.

\section{Author's contribution}

Dr. Anita Sharan: Concept and Data collection

Dr. N. S. Ingole: Data Analysis and Discussion

Funding: No funding sources

Conflict of interest: None declared

Ethical Approval: This study was approved by the Institutional Ethics Committee

\section{Reference}

1. Sanyal RK, West GB. The histamine-heparin complex. J Pharm Pharmacol. 1959;11:548-552. doi: 10.1111/j.20427158. 1959.tb12594.x 
2. Dvorak AM, Monahan RA, Osage JE, Dickersin GR. Crohn's disease: Transmission electron microscopic studies: II. Immunologic inflammatory response. Alterations of mast cells, basophils, eosinophils, and the microvasculature. Human Pathol. 1980;11(6):606-619. doi: 10. 1016/s0046-8177(80)80072-4.

3. Cooke HJ, Fox P, Alferes L, Fox CC, Wolfe SA Jr. Presence of NK1 receptors on a mucosal-like mast cell line, RBL-2H3 cells. Can J Physiol Pharmacol. 1998;76(2):188193.

4. Friedman MM, Kaliner M. In situ degranulation of human nasal mucosal mast cells: ultrastructural features and cell-cell associations. J Allergy Clin Immunol. 1985;76 (1):70-82. doi: 10.1016/0091-6749(85)90807-3.

5. Crow J, Howe S. Mast cell numbers in appendices with threadworm infestation. J Pathol. 1988;154(4):347-351. doi: 10.1002 path.1711540411.

6. Andreou P, Blain S, Du Boulay CE. A histopathological study of the appendix at autopsy and after surgical resection. Histopathol. 1990;17(5):427-431. doi: 10.1111/j. 1365-2559.1990.tb00763.x.

7. Tsuji M, McMahon G, Reen D, Puri P. New insights into the pathogenesis of appendicitis based on immunocytochemical analysis of early immune response. J Pediatr Surg. 1990;25(4):449-452. doi: 10.1016/0022-3468(90) 90392-m.

8. Aravindan KP. Eosinophils in acute appendicitis: possible significance. Indian J Pathol Microbiol. 1997;40 (4):491-498.
9. SV S. Study of mast cell profile In surgically resected Appendices (Doctoral dissertation, Rajiv Gandhi University of Health Sciences).

10. Naik R, Gowda RJ, Pai MR. Mast cell count in surgically resected appendices. J Ind Med Assoc. 1997; 95(11):571-572.

11. Stead RH, Franks AJ, Goldsmith CH, Bienenstock J, Dixon MF. Mast cells, nerves and fibrosis in the appendix: a morphological assessment. J Pathol. 1990;161(3):209219. doi: 10.1002/path.1711610307.

12. Coskun N, Sindel M, Elpek GO. Mast cell density, neuronal hypertrophy and nerve growth factor expression in patients with acute appendicitis. Folia Morphol (Warsz). 2002; 61(4):237-243.

13. Singh UR, Malhotra A, Bhatia A. Eosinophils, mast cells, nerves and ganglion cells in appendicitis. Indian $\mathrm{J}$ Surg. 2008;70(5):231-234. doi: 10.1007/s12262-008-00660. Epub 2008 Nov 26.

14. Amber S, Mathai AM, Naik R, Pai MR, Kumar S, Prasad K. Neuronal hypertrophy and mast cells in histologically negative, clinically diagnosed acute appendicitis: a quantitative immunophenotypical analysis. Indian J Gastroenterol. 2010;29(2):69-73. doi: 10.1007/ s12664-010-0016-1. Epub 2010 May 5.

15. Nemeth L, Reen DJ, O'Briain DS, McDermott M, Puri P. Evidence of an inflammatory pathologic condition in "normal" appendices following emergency appendectomy. Arch Pathol \& Lab Med. 2001;125(6):759-764.

16. Mysorekar VV, Chanda S, Dandeka CP. Mast cells in surgically resected appendices. Indian J Pathol Microbiol. 2006; 49(2):229-233.

\section{How to cite this article?}

Sharan A, Ingole N.S. Study of mast cells in appendicitis: possible significance. Trop J Path Micro 2019;5(11):903-910. doi: 10.17511/jopm.2019.i11.12 